\title{
Posterior Epidural Migration of an Extruded Lumbar Disc Mimicking a Facet Cyst: A Case Report
}

\author{
Young Sun Yoo', Chang II $\mathrm{Ju}^{2}$, Seok Won $\mathrm{Kim}^{2}$, Dong Min $\mathrm{Kim}^{3}$ \\ Departments of ${ }^{I}$ Surgery, ${ }^{2}$ Neurosurgery, ${ }^{3}$ Internal Medicine, Chosun University College of Medicine, Gwangju, Korea
}

Dorsal extradural migration of extruded disc material is clinically uncommon. We report a rare case of posterior epidural migration of an extruded lumbar disc mimicking a facet cyst. A 32-year-old man was admitted to our institute with a 2-week history of severe low back pain and radiating pain in the left leg. The magnetic resonance (MR) images revealed a dorsally located, left-sided extradural cystic mass at the L2-3 level. The initial diagnosis was an epidural facet cyst because of the high signal intensity on MR images and its location adjacent to the facet joint. Intraoperatively, an encapsulated mass of soft tissue adherent to the dural sac was observed and excised. The pathological diagnosis was degenerated disc material. After surgery, the patient experienced complete relief from leg pain.

Key Words: Disc $\cdot$ Cyst $\cdot$ Facet

\section{INTRODUCTION}

Although lumbar disc extrusions are frequently observed in neurosurgical practice, posterior epidural migration of an extruded prolapsed intervertebral disc fragment is rare ${ }^{4,6}$. The migration of disc fragments is generally contained in the anterior epidural space, which is well defined and delineated by the posterior longitudinal ligament and by the lateral membranes attached to it ${ }^{9}$. This paper reports a unique case of the posterior epidural migration of sequestered lumbar disc herniation mimicking an epidural facet cyst, and discusses the imaging and clinical features of this rare condition.

\section{CASE REPORT}

A 32-year-old man with a 2-week history of back pain and severe radiating pain in the left leg was transferred to our institute from a private hospital. He was treated conservatively

- Received: September 3, 2014 - Revised: October 31, 2014

- Accepted: October 29, 2014

Corresponding Author: Seok Won Kim, MD, PhD

Department of Neurosurgery, Chosun University College of Medicine,

365 Pilmun-daero, Dong-gu, Gwangju-city 501-717, Korea

Tel: +82-62-220-3126, Fax: +82-62-227-4575

E-mail:ns64902@hanmail.net/chosunns@chosun.ac.kr

*The present study was supported by grants from the Clinical Medicine Research Institute at Chosun University Hospital (2014)

®This is an Open Access article distributed under the terms of the Creative Commons Attribution Non-Commercial License (http://creativecommons.org/ licenses/by-nc/3.0/) which permits unrestricted non-commercial use, distribution, and reproduction in any medium, provided the original work is properly cited. with anti-inflammatory medication, muscle relaxants, and bed rest in a private hospital; however, the symptoms did not improve. At the time of the visit, clinical examination findings included a straight leg raise test that revealed hypothesia below the L3 nerve root dermatome with unrestricted motion.

Magnetic resonance imaging (MRI) showed a left-sided epidural mass at the L2-3 level. The T2-weighted sagittal and axial MR images revealed a left-sided cystic extradural lesion compressing the dural sac (Fig. $1 \mathrm{~A}$ and B). The lesion showed heterogeneous high signal intensity compared with the degenerated disc on the T2-weighted images. The patient's symptoms were progressive and unresponsive to conservative treatment, and he had restricted movement. Therefore, the patient underwent surgery under a presumptive diagnosis of an intraspinal facet cyst.

After decompressive laminectomy, removal of the mass lesion was performed. The lesion was homogeneous, dark brown in color, firm in consistency, and slightly adherent to the dura
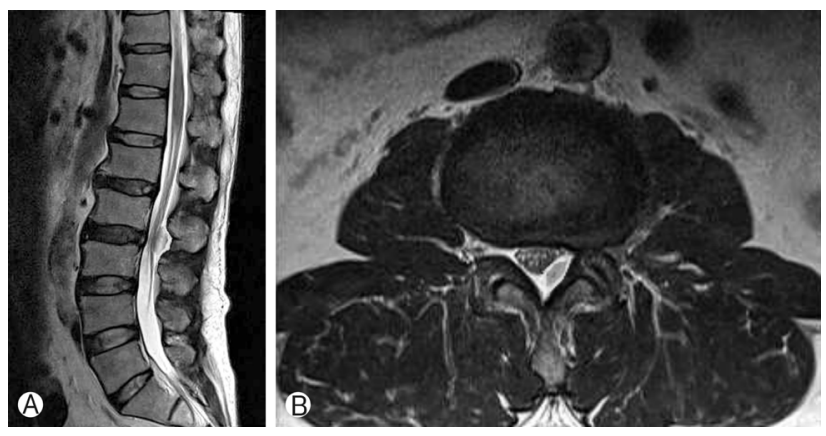

Fig. 1. (A and B) T2-weighted magnetic resonance images of the patient revealed a posterior epidural mass at the L2-3 level. 


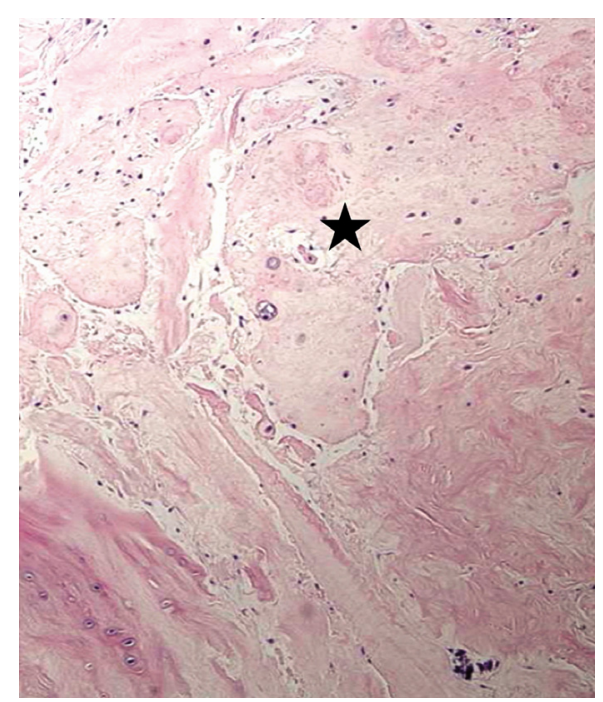

Fig. 2. Histopathological examination of the patient's surgical specimen. Biopsied material shows disc substance (black star) that has paucicellular and homogenous stroma, consistent with nucleus pulposus with degenerative change (hematoxylin and eosin $\times 100$ ).

mater. The pathological examination revealed a cartilaginous mass with partial inflammatory and necrotic material identical to what was expected of a degenerated intervertebral disc (Fig. 2). Six months after surgery, the patient showed no symptom recurrence or neurological aggravation, except for mild numbness.

\section{DISCUSSION}

Disc sequestration can be defined as a herniated disc with perforation of the outermost annulus fibrosus and posterior longitudinal ligament with migration of the disc fragment to the epidural space ${ }^{3)}$. Rarely, sequestrated disc fragments can migrate to the posterior epidural space of the dural sac, and the majority of extruded discs tend to migrate laterally due to the anatomic properties of the anterior epidural space, which is limited dorsally by the posterior longitudinal ligament and ventrally by the vertebral body. In addition, a sagittal midline septum prevents side-to-side displacement. Most symptomatic lumbar disc herniations are observed in the posterolateral position with resulting nerve root irritation. The posterior migration of the disc might present clinically with isolated acute or chronic back pain or significant neurological symptoms such as cauda equina compression ${ }^{1,5)}$.

On computed tomography images, an extradural migrated fragment is usually observed as a posterior mass compressing the dural sac. MRI is the best imaging modality for the spine and its contents. Sequestrated fragments normally show low signal intensity on T1-weighted images, and $80 \%$ of fragments exhibit iso-or slightly high signal intensity on the T2-weighted images relative to the degenerated disc of origin. In the present case, the MR image of the sequestrated fragment was atypical. The high signal intensity on the T2-weighted images in this patient could be explained by the higher water content in the herniated material than on an intact disc or a reparative process that led to transient water gain ${ }^{7}$.

Differential diagnosis often includes hematoma, epidural abscess, tumor, synovial cyst, or ganglion cyst because the extruded disc fragment rarely migrates to the posterior epidural space. Tumors normally enhance uniformly on gadoliniumenhanced MR images. Facet joint cysts can mimic the symptoms of an extruded disc; thus, they can be difficult to diagnose. This is especially the case when there has been hemorrhage into the cyst. On MR images, synovial cysts appear as well-circumscribed extradural cystic lesions that are isointense or hypointense on T1-weighted images, and hyperintense on T2-weighted images. However, signal intensity is highly variable depending on the characteristics of the cyst. An epidural abscess usually presents as a hypointense mass on T1weighted images and a hyperintense mass on T2-weighted imaging with rim enhancement. Conversely, the lack of an associated change in the disc and the adjacent endplates, and the lack of clinical findings of infection suggest another diagnosis. A hematoma is normally isointense or hyperintense on the T1-weighted images, with no enhancement and an associated trauma history ${ }^{2,8)}$. In our case, a preliminary diagnosis of a facet cyst such as a synovial cyst or a ganglion cyst was made because of the high signal intensity on the T2-weighted images compared with the degenerated disc and its location adjacent to the facet joint. We did not include migrated disc in the differential diagnosis due to its unusual location on MRI and unrestricted straight leg raise test during examination. Consequently, treatment consisted of removing the extruded fragment through a hemi- or complete laminectomy. Surgical treatment should be considered to prevent severe neurological deficits in cases of unsuccessful conservative treatment.

\section{CONCLUSION}

We report an atypical posterior epidural migration of an extruded lumbar disc mimicking a facet cyst. Although atypical, posterior epidural migration of an extruded lumbar disc should be included in the differential diagnosis of a posterior extradural mass in the lumbar spine.

\section{REFERENCES}

1. Bonaroti EA, Welch WC: Posterior epidural migration of an ext- 
ruded lumbar disc fragment causing cauda equina syndrome. Spine 23:378-381, 1998

2. Chen CY, Chuang YL, Yao MS, Chiu WT, Chen CL, Chan WP: Posterior epidural migration of a sequestrated lumbar disc fragment: MR imaging findings. AJNR 27:1592-1594, 2006

3. Dosoglu M, Is M, Gezen F, Ziyal MI: Posterior epidural migration of a lumbar disc fragment causing cauda equine syndrome: case report and review of the relevant literature. Eur Spine J 10:348351,2001

4. Hur JW, Lee JW, Rhee JJ, Lee HK: Posterior epidural migration of lumbar disc fragment: Three cases and review of literature. Korean J Spine 8(1):66-69, 2011

5. Kim IS, Lee SW, Son BC, Sung JH: Posterior epidural migration of thoracic disc fragment. J Korea Neurosurg Soc 43:239-241,
2008

6. Lakshmanan P, Ahuja S, Lyons K, Howes J, Davies PR: Sequestrated lumbar intervertebral disc in the posterior epidural space: a report on two cases and review of the literature. Spine J 6: 583-586, 2006

7. Masaryk TJ, Ross JS, Modic MT, Boumphrey F, Bohlman H, Wilber G: High-resolution MR imaging of sequestered lumbar intervertebral discs. Am J Roentgenol 150:1155-1162, 1988

8. Robe P, Martin D, Lenelle J, Stevenaert A: Posterior epidural migration of sequestered lumbar disc fragments. J Neurosurg (Spine) 90:264-266, 1999

9. Schellinger D, Manz HJ, Vidic B, Patronas NJ, Deveikis JP, Muraki AS, et al: Disc fragment migration. Radiology 175:831836, 1990 